\title{
Advanced Voting System Using Fingerprint
}

\author{
TuerxunWaili', Amir NurIman Bin Mohd Zaid², Mohammed Hazim Alkawaz ${ }^{3}$ \\ ${ }^{1,2,3}$ Faculty of Information Sciences and Engineering, Management \& Science University, Malaysia. \\ ${ }^{1}$ School of Electrical Engineering and Computer Science, University of Ottawa, Ottawa, ON, K1N 6N5, Canada \\ ttuerxun@uottawa.ca, amir_nurlman@msu.edu.my,mohammed_hazim@msu.edu.my
}

\begin{abstract}
A Fingerprint is an important identifier for the humans. This paper proposes finger print voting system with Arduino. The majority of the worldwide election were using a paper-based voting rather than using biometric system. The current voting process has safety problems such as authenticity of voters. In proposed system, a voter identity can be proved instantly. All voters' information was stored securely to register in the system. The main objective is to enhance the security in order to prevent duplication and provide a system which reduce the burden for people on conducting a voting. Thus, by implementing this system, user can put their vote with fingerprint instead of paper without doubting about their security. Voting Using Fingerprint reduce the polling time, it provides easy and accurate counting without human labor.
\end{abstract}

Keywords— Biometric, voting system, Fingerprint, Arduino, identification.

\section{INTRODUCTION}

Voting is a kind of method for a group such as a meeting or an electorate to make a decision or express an opinion which often following discussions, debates, or election campaigns. (Engineering et al., 2016) Nowadays, plain paperbased voting is widely used method in world wide. Plain paper-based voting systems are such as paper ballot voting systems, punch card voting systems, and optical mark-sense voting systems [1-2]. Biometric is the science and technology of measuring and analysing biological data [3-4]. Biometrics also can be referred to as technologies that can examine and measure human body characteristics such as fingerprint, voice patterns, facial patterns, hand measurement, DNA and eye retinas which for verification purposes. The formed of field of biometrics has been widen since there are many differentiation types of physical identification.

Human fingerprint is a well-known identifier and the type of biometrics that can be as a choice for law enforcement. The human fingerprint also can be used as human biometric system whereby the fingerprint on every individual are different and unique which shows that the fingerprint cannot be duplicated and manipulated. The purpose of using the fingerprint is for user identification and authentication. The facts that fingerprint recognition is being so popular because of the ease of acquisition, established use, and acceptance when compared to other biometrics and also there are many source of this biometrics on every individual [5].

This paper proposes finger print voting system with Arduino which facilitates error free, fast means of voting in elections. The rest of the paper organized as following. In next section, current situation reviewed and existing commercial products are elaborated/investigated and subsequently compared. In section 3, the methodology and design (hardware and software) of the Fingerprint system is presented. In section 4, results to be discussed. This chapter ends with section 5 conclusion.

\section{LITERATURE REVIEW}

The majority of the worldwide election were using a paper-based voting rather than using fingerprint election system. The past experience of the electoral process required us to sharpen on the use of the latest technology in the electronic voting process. Nowadays, the current voting process has many safety problems, and it is very tricky to prove even simple security aspects about them. Furthermore, there is some possibility to work in the electronic voting system in terms of the authenticity of voters and to protect the electronic voting machine from offenders [6-9]. According to the current system, there is more opportunity on error happening by counting the votes manually which may lead to missed counting and duplicates counting.

Thus, some votes were even manipulated by any other parties which can be lead to inaccurate vote. The counting for the votes is the most important activity in the voting process. If the vote count is reaching to failure, it could lead impact on people attitude towards the party.so voting counting should be clear, reliable and accurate, then only polling station that has a list of all voters assigned to the station and only those listed may vote in that polling station. In following paragraph's, we overview existing commercial fingerprint readers [10-13].

The FingerTec $\mathrm{R}_{3}$ is the latest fingerprint reader from FingerTec which under company of TimeTec Holding for time attendance and door access. This R3 device comes with multiple verification technique such as fingerprint, card and 
password; it comes with 2.4" colour LCD, a touch panel and made durable for frequent usage. It is also coming with huge memory capacity loaded with a sizeable $128 \mathrm{MB}$ SDRAM and $256 \mathrm{MB}$ flash memory capacity that supports up to 100,000 transactions [14].

The FingerTec R3 utilize details matching technology that ensures that only registered users are given access and equipped with TCP/IP connectivity and a USB flash drive is available to transfer transaction logs into the computer when TCP/IP is not available.

The fingerprint scanner ZF10 is from a company called as Dermalog which is suitable for use in variety of application and environments including electronic ID, border control, and passport supply as well as the registration and verification of voter. Thus, it also can be used as security documents like visa. This fingerprint scanner also has a large scanning window ensures easy on processing images. Typically to scan a fingerprint required dry fingerprint, but this fingerprint scanner has an excellent quality that even moist fingerprint can be scanned. It is also can capture fingerprint from a plain tenprints, singleprints and rolled fingerprints [15-16].

Suprema BioLite $\mathrm{N} 2$ is an outdoor fingerprint terminal that gives access time and control features which based on Suprema's latest security platform and biometric technology. BioLite N2 also provides top class security and performance with include Suprema's latest fingerprint algorithm. It contains with rugged IP67 housing and added a flexibility in system design with a multi-class RFID reading technology.
This device also provides a high protection against dust, moisture and even liquid. It is also can capture a fingerprint up to ten fingerprints.

BioFlash USB flash drive has a built-in fingerprint file protection so people would not have to worry about losing their important files to other people. Without a proper fingerprint authentication, an unauthorized user cannot access to view the contents of the USB flash drive. Besides protect the files from alteration by unauthorized users, it is also can prevent them from check out the contents within the drive. BioFlash USB flash drive does not need any software installation before using the fingerprint authentication protection feature and can be plug and play device. The capacity storage of the flash drive is fom $128 \mathrm{MB}$ to $1 G B$ and can capture only 5 fingerprint maximum.

MorphoWave Compact is a device developed by company name IDEMIA. This device using a touchless 3D fingerprint to capture people fingerprint. In less than one second, MorphoWave Compact have the patented touchless sensor technology scans four to ensures the most reliable and accurate fingerprint matching for maximum security. This ergonomic touch less solution carries an unmatched combination of security, throughput and convenience. It is also have multifactor authentication that supports MiFARE, DESFire cards, PIN code, and also capable of scanning QR codes for visitor management.

\begin{tabular}{|c|c|c|c|c|c|}
\hline $\begin{array}{l}\text { Related } \\
\text { Products } \\
\text { Features }\end{array}$ & FingerTec $\mathrm{R}_{3}$ & $\begin{array}{c}\text { Fingerprint } \\
\text { Scanner ZF10 }\end{array}$ & BioLite N2 & $\begin{array}{c}\text { BioFlash USB } \\
\text { Drive }\end{array}$ & $\begin{array}{l}\text { MorphoWave } \\
\text { Compact }\end{array}$ \\
\hline $\begin{array}{c}\text { Technology } \\
\text { used }\end{array}$ & $\begin{array}{l}\text { Fingerprint, } \\
\text { card, } \\
\text { password }\end{array}$ & Fingerprint & $\begin{array}{l}\text { Fingerprint, } \\
\text { RFID }\end{array}$ & Fingerprint & $\begin{array}{c}\text { Touchless 3D } \\
\text { fingerprint, RFID } \\
\text { card }\end{array}$ \\
\hline Purpose & Door access & $\begin{array}{c}\text { Security } \\
\text { documents }\end{array}$ & $\begin{array}{l}\text { For outdoor } \\
\text { environment }\end{array}$ & $\begin{array}{c}\text { Save } \\
\text { important } \\
\text { files } \\
\end{array}$ & $\begin{array}{c}\text { Door or gate } \\
\text { access }\end{array}$ \\
\hline $\begin{array}{l}\text { Number of } \\
\text { fingerprint } \\
\text { capture }\end{array}$ & Only one & $\begin{array}{l}\text { Up to ten } \\
\text { fingerprint } \\
\text { once }\end{array}$ & Only one & $\begin{array}{c}\text { Five } \\
\text { fingerprint } \\
\text { maximum }\end{array}$ & $\begin{array}{l}\text { Four fingerprint } \\
\text { maximum }\end{array}$ \\
\hline $\begin{array}{l}\text { Fingerprint } \\
\text { quality }\end{array}$ & $\begin{array}{c}\text { Dry, moist, } \\
\text { dust }\end{array}$ & Dry, moist & $\begin{array}{l}\text { Dry, moisture, } \\
\text { dust, liquid }\end{array}$ & Dry & None \\
\hline
\end{tabular}

\section{RESEARCH METHODOLOGY}

The tools and hardware is used in order to develop the system. Since there are many available software and hardware today, so it must be chosen based the requirement. The system consists of fingerprint module, Arduino Uno micro controller board, power supply and LCD screen. Following is a block diagram of the system. 


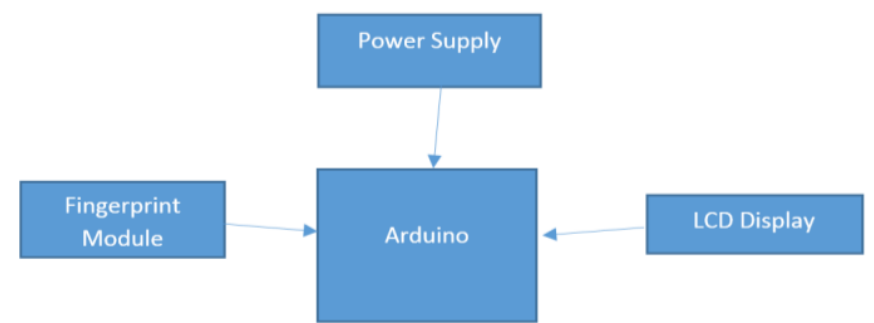

Fig. 1 Block Diagram of Fingerprint voting system

1) Arduino IDE: is a software, it stands for Integrated Development Environment. It comes with the physical programmable circuit board which known as Arduino Boards. This software is specifically used for write, compile and upload source code into the Arduino devices. Moreover, Arduino IDE is an open source software and available to install and start to compiling the code. It is also support both $\mathrm{C}$ and $\mathrm{C}++$ languages which making it understandable and learn it easier.

2) The Arduino Uno a microcontroller board and it is used to make a prototype of the system. It contains 14 digital input or output pins, six analog inputs, a $16 \mathrm{MHz}$ crystal oscillator, a power slot, a usb port, an ICSP header and a reset button. To use Arduino Uno is by power it with AC-to-DC adapter or connect it to a computer with a USB cable to get started.

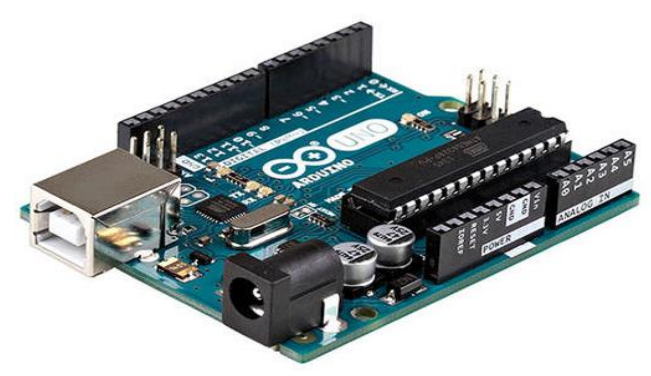

Fig. 1 Arduino Uno microcontroller board

3) Fingerprint module is an input device which used for fingerprint processing and capturing a digital image of the fingerprint pattern. For fingerprint enrolling process, user needs to enter the finger two times in order for the system generate a template of the finger based on processing results and store the template.

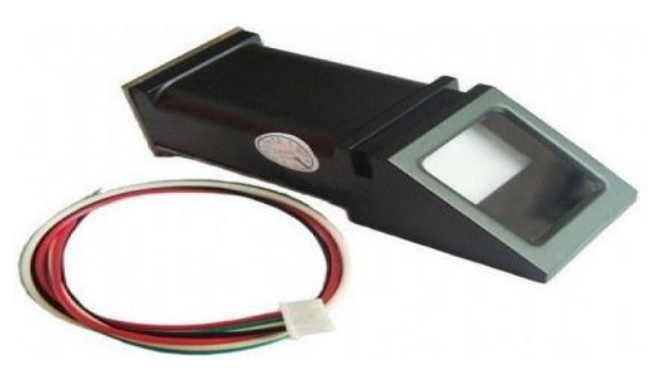

Fig. 3 Fingerprint input module
This LCD Display will display any information from the system.

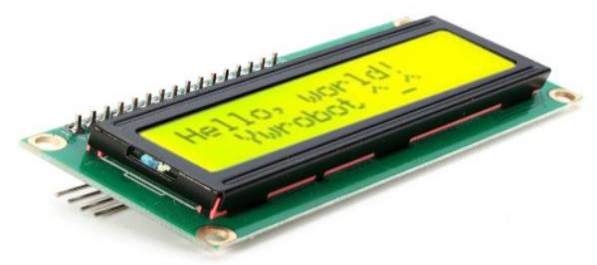

Fig. 4 the LCD Display

4) Interface Design, Figure 5 depicts the interface of the fingerprint voting system. It consists of the capture of fingerprint, status whether it is failed or succeed, language, save image and match or fingerprint.

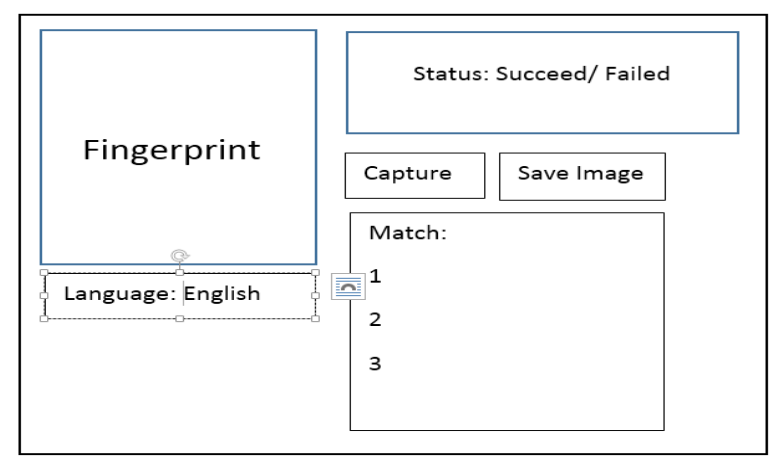

Fig. 5 the LCD Display

\section{EXPERIMENTS AND RESULTS}

The Fingerprint Voting System is to allow user to put their vote on their chosen candidate by using a fingerprint authentication.

The main objective as stated before is to enhance the security in order to prevent duplication and provide a system which reduce the burden for people on conducting a voting. Thus, by implementing this system, user can put their vote with fingerprint instead of paper without doubting about their security.

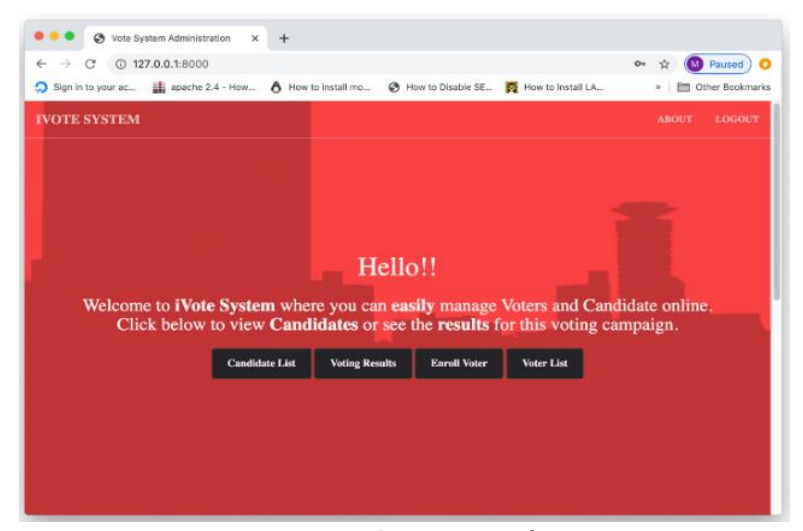

Fig. 6 the user interface 


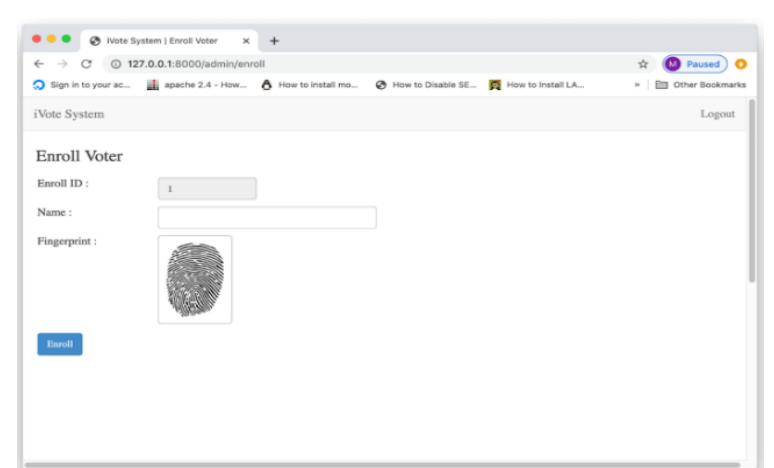

Fig. 7 stored fingerprint image

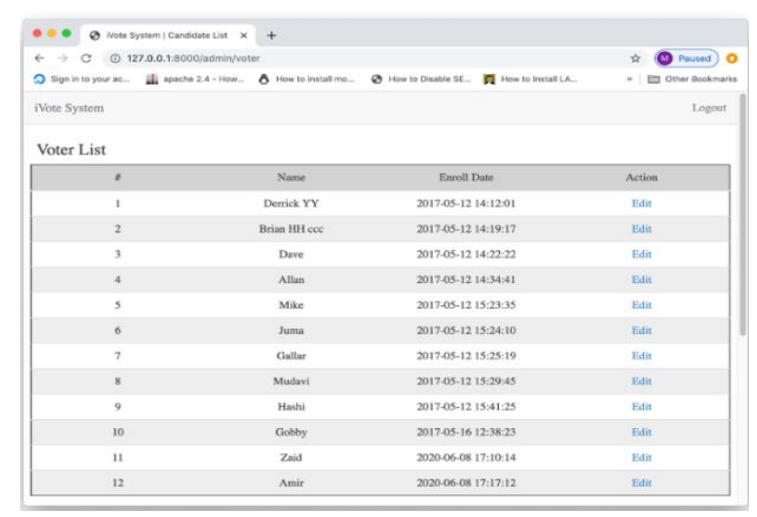

Fig. 8 the database of voters

\section{CONCLUSIONS}

The Fingerprint Voting System is to allow user to put their vote on their chosen candidate by using a fingerprint authentication. The main objective as stated before is to enhance the security in order to prevent duplication and provide a system which reduce the burden for people on conducting a voting. Thus, by implementing this system, user can put their vote with fingerprint instead of paper without doubting about their security.

\section{ACKNOWLEDGMENT}

The Authors are grateful to Faculty of Information Sciences and Engineering, Management and Science University, Malaysia for their support.

\section{REFERENCES}

[1] B. Rudrappa. Gujanatti, Shivaram N. Tolanur, Murughendra S. Nemagoud, \& Shanta S. Reddy, Sangameshwar Neelagund. A Finger Print based Voting System. International Journal of Engineering Research and, V4(05), 887-892. (2015).

[2] T. Kanagasabai, Piratheepan, A., Researcher, I., \& Nagarathnam, T. Fingerprint Voting System Using Arduino. 25(January 2018), 1793-1802. (2017)

[3] U.A. Wakpanjar., Shamkule, A. A., Tiwari, R. J., Sagane, S. C., Akshay, P., \& Raut, N. V. Online voting system using fingerprint scanner. 3421-3423. (2018)
[4] P., Abdallah, A., Mohammed, E., Abdallah, E., Osman, A. Ali, M. Implementation of Electronic Voting System Using Fingerprint Recognition Technique. (2016).

[5] Y. Lee, \& Won, D. (2012). A practical and secure electronic election system. ETRI Journal.

[6] P. Lin, Li, Q., Fan, Q., Gao, X., \& Hu, S. A real-time location-based services system using WiFi fingerprinting algorithm for safety risk assessment of workers in tunnels. Mathematical Problems in Engineering. (2014)

[7] B. Molina, Olivares, E., Palau, C. E., \& Esteve, M. A multimodal fingerprint-based indoor positioning system for airports. (2018)

[8] D. Kumar, \& Begum, T. U. S. A novel design of electronic voting system using fingerprint. International Journal of Innovative Technology \& Creative Engineering, 1(1), 12-19. (2011)

[9] R.S. Raj, Raghavendra, A., Madhushree, K. R., \& Bhargavi, D. An online voting system using biometric fingerprint and Aadhaar card. IJCAT International Journal of Computing and Technology, 1(4), 87-92(2014)

[10] A.S. Falohun, Fenwa, O. D., \& Ajala, F. A. A Fingerprint-based Age and Gender Detector System using Fingerprint Pattern Analysis. International Journal of Computer Applications, 136(4), 09758887. (2016)

[11] P.S. Naidu, Kharat, R., Tekade, R., Mendhe, P., \& Magade, V. Evoting system using visual cryptography \& secure multi-party computation. In 2016 International Conference on Computing Communication Control and automation (ICCUBEA) (pp. 1-4). IEEE. (2016).

[12] A. Piratheepan, Sasikaran, S., Thanushkanth, P., Tharsika, S., Nathiya, M., Sivakaran, C., ... \& Thiruthanigesan, K. Fingerprint Voting System Using Arduino. Middle-East Journal of Scientific Research, 25(8), 1793-1802. (2017)

[13] S. Chakraborty, Mukherjee, S., Sadhukhan, B., \& Yasmin, K. T. Biometric voting system using aadhar card in india. International journal of Innovative research in Computer and Communication Engineering, 4(4).(2016)

[14] B.A. Oke, Olaniyi, O. M., Aboaba, A. A., \& Arulogun, O. T. Developing multifactor authentication technique for secure electronic voting system. International Conference on Computing Networking and Informatics (pp. 1-6). IEEE. (2017,)

[15] M.M. Min, \& Thein, Y. Intelligent fingerprint recognition system by using geometry approach. In 2009 International Conference on the Current Trends in Information Technology (CTIT) (pp. 1-5). IEEE. (2009)

[16] T. Waili, T., Nor, R. M., Sidek, K. A., Abubakar, A., Chiroma, H., \& Herawan, T. (2019). A Framework for Non-contact ECG Signal Detection Device on Smart Chair and Its Implementation. In Proceedings of the International Conference on Data Engineering 2015 (DaEng-2015) (pp. 639-646). Springer, Singapore. 